\title{
miR-455-5p functions as a potential oncogene by targeting galectin-9 in colon cancer
}

\author{
QIANQIAN YANG ${ }^{1 *}$, CHEN HOU $^{2 *}$, DA HUANG $^{1}$, CHUNBO ZHUANG $^{1}$, \\ WEICHAO JIANG $^{1}$, ZHI GENG ${ }^{1}$, XIAOBEI WANG ${ }^{1}$ and LIHUA HU ${ }^{1}$ \\ ${ }^{1}$ Department of Clinical Laboratory, Union Hospital, Tongji Medical Collage, \\ Huazhong University of Science and Technology, Wuhan, Hubei 430022; ${ }^{2}$ Department of Blood Transfusion, \\ Xinhua Hospital, School of Medicine, Shanghai Jiao Tong University, Shanghai 200092, P.R. China
}

Received September 10,2015; Accepted November 3, 2016

DOI: $10.3892 / 01.2017 .5608$

\begin{abstract}
Although there is evidence that galectin-9 is a critical factor in health and disease, the upstream regulatory microRNA (miRNA or miR) of the protein remains poorly defined. miR-455-5p is characterized as a tumor-associated miRNA in cancer research. However, the actual role of miR-455-5p with respect to inhibiting or promoting tumorigenesis in colon cancer is unclear. The present study aimed to investigate the expression, role and target regulation association of galectin-9 and miR-455-5p in colon cancer. Western blot analysis and reverse transcription-quantitative polymerase chain reaction were used for the detection of the expression levels of galectin- 9 and miRNAs. Cell Counting kit- 8 test was used for the evaluation of cell proliferation, while flow cytometry was used for cell apoptosis analysis. A potential interaction between galectin- 9 and miR-455-5p was predicted by target prediction programs and confirmed by luciferase assay and transfection with miRNA mimics. The present study revealed that elevated expression of galectin- 9 and miR-455-5p in colon cancer was associated with HT29 cell proliferation and apoptosis. Furthermore, the present study demonstrated that miR-455-5p reduced galectin- 9 expression by directly targeting its 3'-untranslated region. These data suggest that miR-455-5p functions as a potential oncogene in colon cancer by targeting galectin- 9 .
\end{abstract}

Correspondence to: Professor Lihua Hu, Department of Clinical Laboratory, Union Hospital, Tongji Medical Collage, Huazhong University of Science and Technology, 1277 JieFang Avenue, Wuhan, Hubei 430022, P.R. China

E-mail: zztyqq@126.com

*Contributed equally

Key words: galectin-9, microRNA, miR-455-5p, colon cancer

\section{Introduction}

Colon cancer is one of the most common types of gastroenteric tumors for males and females, accounting for a large proportion of cancer-associated mortalities worldwide $(1,2)$. Due to changes in human environment, nutritional habits and life style, the incidence rate of colon cancer has increased worldwide over the last 20 years $(3,4)$. Colon cancer occurs in a multi-step process, and metastasis is the major cause of morbidity and mortality, with $\sim 1 / 3$ of patients with colon cancer ultimately developing metastatic disease (5). The use of chemotherapy and surgical resection for the treatment of malignant colon cancer is increasing, but the results of these treatments are typically poor (6). Therefore, investigation into the molecular mechanism underlying the pathogenesis and progression of colon cancer, and the search for specific, sensitive biomarkers for the early diagnosis and prognosis prediction of colon cancer is required.

There are 11 galectin family members identified in humans at present (7), including galectin-9, which is a type 1 tandem repeat containing a $\mathrm{C}$-terminal coding region determinant (C-CRD) of 149 amino acids and an N-terminal CRD of 148 amino acids (8). The protein was first identified as an eosinophil chemoattractant and activation factor $(9,10)$, and later confirmed as a physiological ligand of T-cell immunoglobulin and mucin domain 3 (11). Galectin-9 is known to exhibit a variety of biological functions, including cell aggregation, adhesion, proliferation, apoptosis and modulation of inflammation $(12,13)$. Attention has previously been focused on the molecular mechanism of galectin-9 in malignant tumors. For example, Nobumoto et al (14) confirmed that galectin-9 suppressed tumor metastasis by blocking adhesion to the endothelium and extracellular matrices. A study by Zhang et al (15) demonstrated that galectin- 9 acted as a prognostic factor with antimetastatic potential in hepatocellular carcinoma. However, the expression and role of galectin-9 in human colon cancer have not been fully verified.

MicroRNAs (miRNAs or miRs) are a class of non-coding single-stranded RNA molecules with $~ 22-24$ nucleotides (16). miRNAs serve a pivotal role in the regulation of target gene expression by binding to the 3 '-untranslated regions (3'-UTR) of their target messenger RNA (mRNA), leading to mRNA 
degradation or inhibition of translation into protein $(17,18)$. Currently, $>2,042$ mature miRNAs have been identified in humans, which constitute a large network that regulates the expression of $\leq 30 \%$ of all cellular proteins $(19,20)$. The expression of miRNAs is regulated developmentally and spatially, and increasing evidence has demonstrated that miRNAs modulate a variety of cellular functions, including cell differentiation, proliferation and death (21). Numerous studies have indicated the involvement of miRNAs in the progression and metastasis of numerous types of cancer, suggesting that miRNAs may be used in future therapeutic and diagnostic applications (22-24).

At present, the upstream regulatory miRNA of galectin-9 is undefined. The purpose of the present study was to investigate the upstream regulatory miRNA of galectin- 9 in colon cancer. The present study demonstrated that elevated expression levels of galectin-9 and miR-455-5p in colon cancer were associated with HT29 cell proliferation and apoptosis, and confirmed that miR-455-5p directly targets galectin-9 3'-UTR and negatively regulates galectin- 9 expression in colon cancer cells.

\section{Materials and methods}

Tissue collection. Paired resected surgical specimens from primary tumors and corresponding adjacent non-tumor sites were obtained from 10 patients that underwent primary surgical resection of colon cancer between June and October 2013 at the Department of Gastrointestinal Surgery of Wuhan Union Hospital (Wuhan, China). Tissue specimens were confirmed separately by two experienced pathologists under double-blinded conditions. None of the patients received any therapy prior to operation. The demographic features and clinicopathological data were reviewed in the patients' medical records. The present study was approved by the Ethics Committee of Wuhan Union Hospital and performed with informed consent obtained from all patients. All samples were frozen in liquid nitrogen and stored at $-80^{\circ} \mathrm{C}$ for future molecular analyses.

Cell culture. The human colon cancer HT29 cell line was purchased from the Shanghai Institute of Biochemistry and Cell Biology (Shanghai, China), and cultured in Dulbecco's modified Eagle's medium (DMEM; HyClone; GE Healthcare Life Sciences, Logan, UT, USA) supplemented with $10 \%$ fetal bovine serum (Gibco; Thermo Fisher Scientific, Inc., Waltham, MA, USA), $1 \mathrm{U} / \mathrm{ml}$ penicillin (Gibco; Thermo Fisher Scientific, Inc.) and $1 \mu \mathrm{g} / \mathrm{ml}$ streptomycin (Gibco; Thermo Fisher Scientific, Inc.). All cultures were maintained at $37^{\circ} \mathrm{C}$ in a humidified atmosphere with $5 \% \mathrm{CO}_{2}$.

Reverse transcription-quantitative polymerase chain reaction $(R T-q P C R)$. Total RNA and miRNA were extracted from the cells and tissues using TRIzol reagent (Invitrogen; Thermo Fisher Scientific, Inc., Wilmington, DE, USA) according to the manufacturer's protocol. RNA quantity and quality were determined using $1 \%$ agarose gel electrophoresis and an optical density 260/280 absorption ratio of $>1.8$ using the NanoDrop 2000 (Thermo Fisher Scientific, Waltham, MA, USA). Complementary DNA was synthesized using a PrimeScript RT Reagent kit (Takara Biotechnology Co., Ltd., Dalian, China) and a MyCycler ${ }^{\mathrm{TM}}$ thermal cycler (Bio-Rad
Laboratories, Inc., Hercules, CA, USA) according to the manufacturer's protocol. The cycling conditions were as follows: $37^{\circ} \mathrm{C}$ for $15 \mathrm{~min}$, followed by $85^{\circ} \mathrm{C}$ for $15 \mathrm{sec}$ and then $4^{\circ} \mathrm{C}$. RT-qPCR was performed using SYBR ${ }^{\circledR}$ Premix Ex Taq ${ }^{\text {TM }}$ II (Takara Biotechnology Co., Ltd.) and Mx3000P qPCR system (Agilent Technologies, Inc., Santa Clara, CA, USA). Each reaction was performed in a total volume of $20 \mu$, containing $10 \mu \mathrm{l} \mathrm{SYBR}{ }^{\circledR}$ Premix Ex Taq ${ }^{\mathrm{TM}} \mathrm{II}, 2 \mu \mathrm{l}$ primers, $2 \mu$ l template complementary DNA, $0.4 \mu \mathrm{l}$ ROX Reference Dye (50X; Takara Biotechnology Co., Ltd.) and $5.6 \mu \mathrm{l}$ distilled $\mathrm{H}_{2} \mathrm{O}$. Cycling conditions were as follows: $95^{\circ} \mathrm{C}$ for $30 \mathrm{sec}$, followed by 40 cycles of amplification $\left(95^{\circ} \mathrm{C}\right.$ for $5 \mathrm{sec}, 60^{\circ} \mathrm{C}$ for $30 \mathrm{sec}$ and $72^{\circ} \mathrm{C}$ for $30 \mathrm{sec}$ ). RT-qPCR was performed in triplicate for each sample. The expression of each type of RNA and miRNA was defined from the quantification cycle $(\mathrm{Cq})$, and relative expression levels were calculated using the $2^{-\Delta \Delta \mathrm{Cq}}$ method (25). Human GAPDH and U6 were used as the housekeeping genes for the amplifications. The PCR primers used in the present study were described previously (26).

Western blot analysis. Proteins were extracted from the cells and tissues using radioimmunoprecipitation assay lysis buffer (Beyotime Institute of Biotechnology, Haimen, China), and the lysates were cleared by centrifugation at $13,523 \mathrm{x} g$ at $4^{\circ} \mathrm{C}$ for $15 \mathrm{~min}$. Subsequent to their concentration being measured with the Pierce BCA Protein Assay kit (Thermo Fisher Scientific, Inc.), the proteins were mixed with SDS loading buffer, separated by $10 \%$ SDS-PAGE and transferred onto a polyvinylidene difluoride membrane (EMD Millipore, Billerica, MA, USA). Subsequent to the blockage of nonspecific binding sites for $1 \mathrm{~h}$ with $5 \%$ nonfat milk, the blots were incubated with rabbit anti-human galectin-9 (dilution, 1:1,000; catalog no. YT1841; ImmunoWay Biotechnology Company, Plano, TX, USA) or anti- $\beta$-actin (dilution, 1:2,000; catalog no. 12,620; Cell Signaling Technology, Inc., Danvers, MA, USA) primary antibodies at $4^{\circ} \mathrm{C}$ overnight, followed by incubation with goat anti-rabbit horseradish peroxidase-conjugated secondary antibody (dilution, 1:2,000; catalog no. 7074; Cell Signaling Technology, Inc.) at room temperature for $1 \mathrm{~h}$. Proteins were visualized with Pierce ${ }^{\mathrm{TM}}$ ECL Western Blotting Substrate (Thermo Fisher Scientific, Inc.). The immunoblots were visualized using ImageJ software version 1.49 (National Institutes of Health, Bethesda, MD, USA).

Flow cytometric analysis for apoptosis. HT29 cells transfected with Galectin-9/pcDNA3.1 vector were seeded in 6 -well plates $\left(1 \times 10^{6}\right.$ cells/well) and cultured with DMEM in a humidified chamber at $37^{\circ} \mathrm{C}$ in $5 \% \mathrm{CO}_{2}$ for $24 \mathrm{~h}$. Cell apoptosis was evaluated using an Annexin-V-FLUOS Staining kit (catalog no. 11858777001; Roche Applied Science, Mannheim, Germany). Briefly, $1 \times 10^{6}$ cells were washed with PBS and centrifuged at $200 \times \mathrm{x}$ at room temperature for $5 \mathrm{~min}$. Then, the cell pellets were resuspended in $100 \mu \mathrm{l}$ Annexin-V-FLUOS labeling solution (containing $2 \mu 1$ Annexin-V-FLUOS labeling reagent, $2 \mu 1$ propidium iodide solution and $96 \mu$ incubation buffer) and incubated for $10-15 \mathrm{~min}$ at $15-25^{\circ} \mathrm{C}$. Apoptosis was assessed by flow cytometry using FACSCalibur (BD Biosciences, Franklin Lakes, NJ, USA). Non-transfected HT29 cells were used as 
a negative control. Each group was independently evaluated three times.

Cell proliferation assay. At $24 \mathrm{~h}$ post-transfection, the cells were digested using trypsin (Wuhan Amyjet Scientific Co., Ltd., Wuhan, China) and washed twice with PBS (Sangon Biotech Co., Ltd., Shanghai, China), and then seeded into 96-well plates at a concentration of $2 \times 10^{3}$ cells/well. Cell Counting kit-8 (CCK-8; Dojindo Molecular Technologies, Inc., Kumamoto, Japan) was used to assess the cell proliferation activity at $0,24,48$ and $72 \mathrm{~h}$. A total of $10 \mu \mathrm{lCCK}-8$ was added to each well, and following $2 \mathrm{~h}$ of incubation at $37^{\circ} \mathrm{C}$, the optical density value at $450 \mathrm{~nm}$ was determined with a scan reader (MTX Lab Systems, Inc., Vienna, VA, USA).

Target prediction. miRNAs that target galectin-9 were identified by examining the galectin-9 3'-UTR with bioinformatics algorithms that predict miRNA target sites. Specifically, miRanda (www.microrna.org) and TargetScan (www. targetscan.org) were used for the analysis of the alignment between miRNAs and the 3'-UTR of galectin-9.

Plasmid construction, miRNA synthesis and transfection. The plasmid (p) cytomegalovirus (CMV) -galectin-9-3'-UTR wild-type (WT), pCMV-galectin-9-3'-UTR mutant (MU) and galectin-9 overexpression vector (Galectin-9/pcDNA3.1) were constructed as described previously (26). The specific primers for galectin-9 3'UTR-WT were: Forward, 5'-ATAGAATTC GCGGCTTCCTGGCCCTG-3' and reverse, 5'-CGCAAG CTTTGAATGTGCCAACAAGCA-3'. The specific primers for galectin-9 3'UTR-MU were: Forward, 5'-AATGAA AATGCTTGTTGGAATTCTCAAAGCTTATCGAT-3' and reverse, 5'-TTTCCAGGAGGGGTGAAGAATTCGTGC ACGGTGCAAGG-3'. miR-455-5p and miR-control (used as a negative control) mimics were synthesized by Guangzhou RiboBio Co., Ltd. (Guangzhou, China). The cells were transiently transfected using Lipofectamine 2000 transfection reagent (Invitrogen; Thermo Fisher Scientific, Inc., USA) for $24 \mathrm{~h}$, according to the protocol of the manufacturer.

Luciferase reporter gene assay. The HT29 cells were plated in a 96-well plate and co-transfected with miR-455-5p or control mimics and pCMV-galectin-93'-UTR-WT or pCMV-galectin-9 3'-UTR-MU, in addition to the pRL-TK vector (Promega Corporation, Madison, WI, USA), using Lipofectamine 2000. The cells were collected $24 \mathrm{~h}$ after transfection, and the luciferase activity was analyzed using the Dual-Luciferase Reporter Assay System (Promega Corporation) in a Modulus single-tube multimode reader (Turner BioSystems, Inc.; Promega Corporation). The pRL-TK vector (Promega Corporation, Madison, WI, USA) that provided the constitutive expression of Renilla luciferase was co-transfected as an internal control to correct for differences between transfection and harvest efficiencies. The transfections were performed at least twice in independent experiments.

Statistical analysis. The Student's $t$-test was used to evaluate statistical significance. $\mathrm{P}<0.05$ was considered to indicate a statistically significant difference. All experiments were repeated $>3$ times, and the results from a representative experiment were selected to draw diagrams and data analysis. All data were statistically analyzed using GraphPad Prism 5.0 (GraphPad Software, Inc., La Jolla, CA, USA).

\section{Results}

Expression and role of galectin-9 in colon cancer tissue and in colon cancer cell proliferation and apoptosis. The expression levels of galectin-9 in colon cancer tissues and the corresponding adjacent tissues from 10 patients were determined using RT-qPCR and western blot analysis. Galectin-9 was revealed to be significantly downregulated in colon cancer tissue at the mRNA and protein level compared with the corresponding adjacent tissue $(\mathrm{P}=0.0405$ and $\mathrm{P}=0.0037$; Fig. $1 \mathrm{~A}$ and $\mathrm{B}$, respectively).

To investigate the role of galectin-9 in colon cancer cell apoptosis, flow cytometric analysis was evaluated using an Annexin-V-FLUOS Staining kit. The present study revealed that overexpression of galectin-9 promoted HT29 cell apoptosis (Fig. 1C).

In order to additionally examine the role of galectin- 9 in colon cancer cell proliferation, the present study constructed the galectin-9 overexpression vector Galectin-9/pcDNA3.1 and transfected it into HT29 cells. CCK-8 assay revealed that overexpression of galectin-9 inhibited HT29 cell proliferation (Fig. 1D).

Expression of candidate miRNAs and role of $\mathrm{miR}-455-5 \mathrm{p}$ in colon cancer. The target prediction programs miRanda and TargetScan were used to predict and identify miRNAs that may target galectin-9. The present study identified four miRNAs (miR-22, 296-3p, 455-5p and 491-5p) that were potential regulators of galectin-9 (26).

The expression of the aforementioned four miRNAs in colon cancer tissues and corresponding adjacent tissues was determined. The results indicated that the expression of miR-22 was significantly downregulated in colon cancer tissue compared with the corresponding adjacent tissue $(\mathrm{P}=0.0397$; Fig. 2A), while miR-455-5p was significantly upregulated in colon cancer tissue compared with the corresponding adjacent tissue ( $\mathrm{P}=0.0346$; Fig. 2C). miR-296-3p and miR-491-5p did not exhibit a significant difference in expression between colon cancer tissue and the corresponding adjacent tissue $(\mathrm{P}=0.9063$ and $\mathrm{P}=0.9477$; Fig. $2 \mathrm{~B}$ and $\mathrm{D}$, respectively). miR-455-5p was selected in the present study for further experiments, as its expression level exhibited an inverse correlation with galectin-9 expression.

The present study subsequently examined the role of miR-455-5p in colon cancer cell apoptosis and proliferation, revealing that miR-455-5p inhibited HT29 cell apoptosis (Fig. 3A) and promoted HT29 cell proliferation (Fig. 3B).

miR-455-5p directly targets and downregulates galectin-9 in HT29 cells. To validate whether galectin-9 was a direct target of miR-455-5p, the present study constructed galectin-9 3'-UTR-WT and galectin-9 3'-UTR-MU plasmids (Fig. 4A), and transfected them into HT29 cells with miR-control or miR-455-5p mimic, respectively. Luciferase activity was measured $24 \mathrm{~h}$ after transfection. The luciferase activity in the cells co-transfected with miR-455-5p mimic 
A
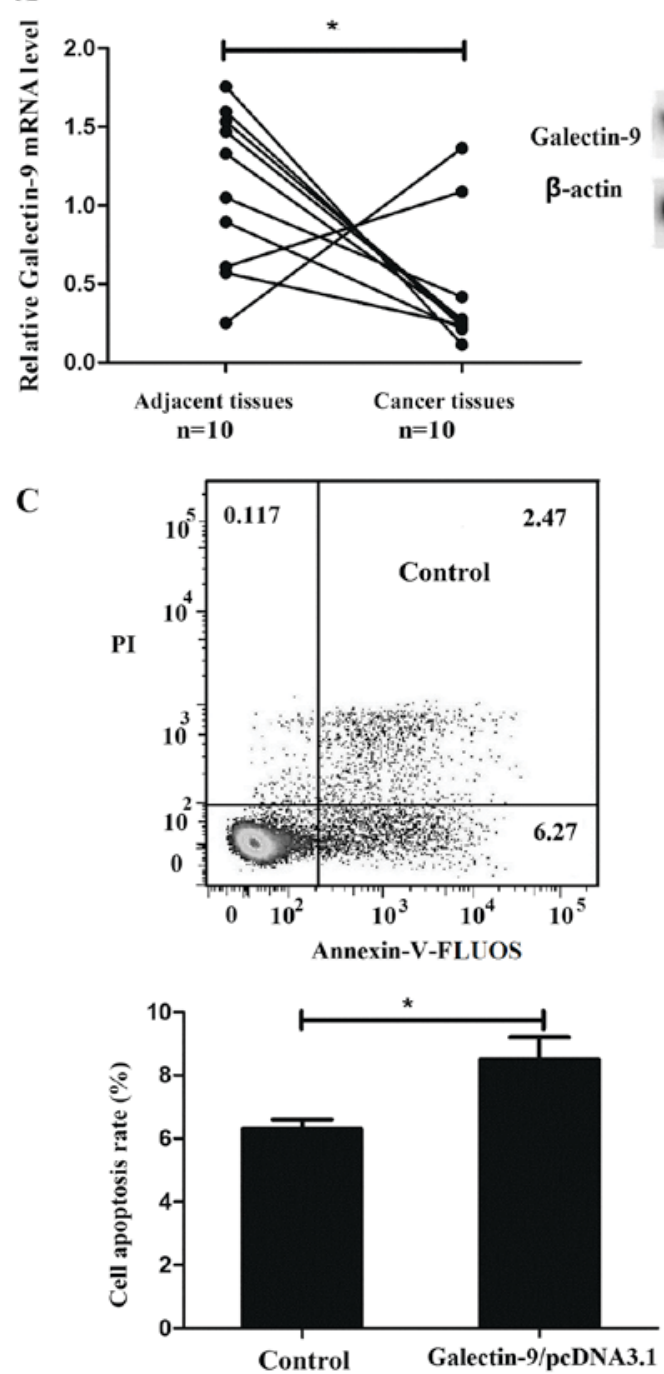

B

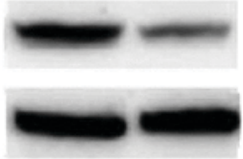

Adjacent cancer
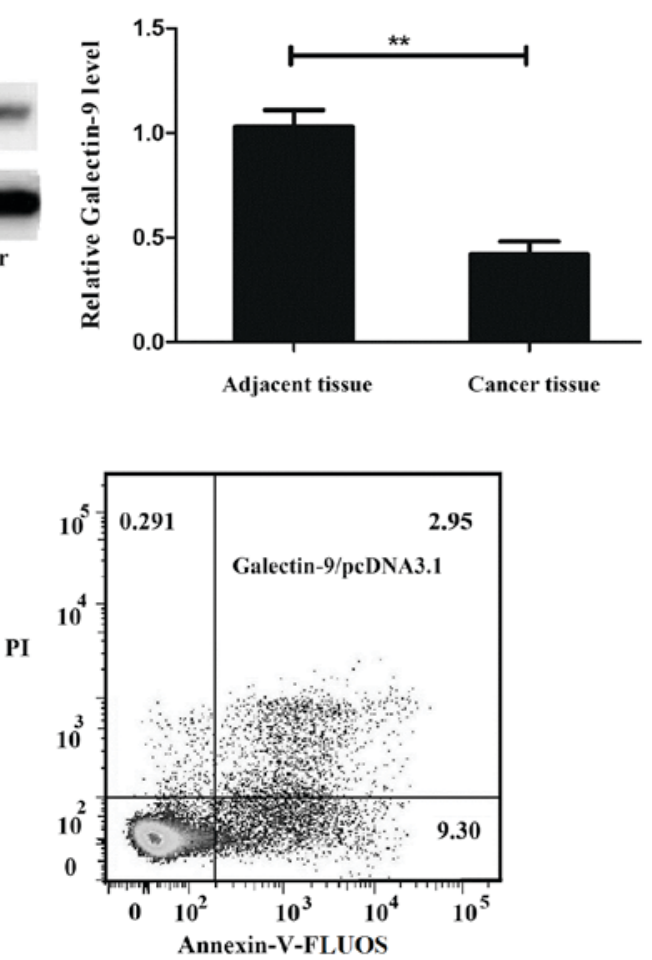

D

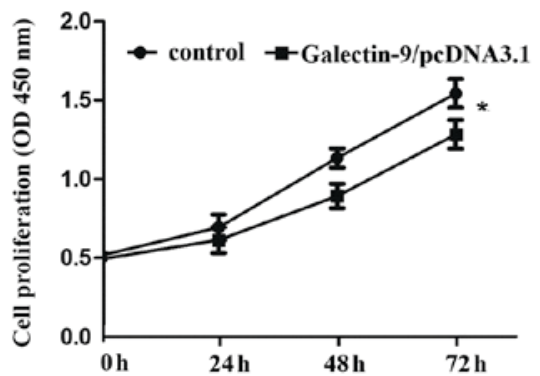

Figure 1. Expression of galectin-9 in colon cancer tissue, and its role in cell apoptosis and proliferation. (A) Galectin-9 mRNA level was significantly downregulated in colon cancer tissues compared with that in the corresponding adjacent tissues, $n=10$. (B) Galectin- 9 protein level was significantly downregulated in colon cancer tissues compared with that in the corresponding adjacent tissues, $\mathrm{n}=10$. (C) Overexpression of galectin-9 promoted HT29 cell apoptosis . (D) Overexpression of galectin-9 inhibited cell proliferation. " $\mathrm{P}<0.05,{ }^{* *} \mathrm{P}<0.01$. mRNA, messenger RNA; OD, optical density; PI, propidium iodide.

and galectin-9 3'-UTR-WT plasmid significantly decreased compared with that in cells co-transfected with miR-control mimic or galectin-9 3'-UTR-MU plasmid (Fig. 4B).

To investigate the potential correlation between miR-455-5p and galectin-9 mRNA/protein expression in colon cancer cells, miR-control or miR-455-5p mimic were transfected into HT29 cells, and the mRNA/protein expression levels of galectin-9 were examined by RT-qPCR and western blot analysis, respectively. The expression of galectin-9 mRNA ( $\mathrm{P}=0.0043$; Fig. 4C) and protein ( $\mathrm{P}=0.0027$; Fig. 4D) were observed to be significantly downregulated subsequent to transfection with miR-22 mimics, compared with the results obtained for the miR-control. These findings indicate that galectin- 9 is a direct downstream target of miR-455-5p in HT29 cells.

\section{Discussion}

Galectin-9 has been detected extracellularly and intracellularly, and the expression of the protein is widely distributed in tissues $(27,28)$. Indeed, the available results suggest that galectin- 9 expression is frequently altered when comparing tumor tissue with normal tissue (29). In addition, one study supports the hypothesis that galectin-9 is involved in several aspects of tumor progression (30). Galectin-9 also induces the apoptosis of various cell types, including human melanoma, $\mathrm{T}$ cell and leukemia cell lines $(13,31,32)$. The present study explored the expression and potential role of galectin-9 in colon cancer, and noticed that galectin- 9 was significantly downregulated in colon cancer tissue compared with corresponding adjacent tissue. Furthermore, overexpression of galectin-9 inhibited HT29 cell proliferation and promoted HT29 cell apoptosis. These results suggest that galectin-9 is important in colon cancer.

Numerous studies highlight the impact of miRNA on the tumorigenesis of human carcinoma (33-35). To define the upstream regulatory miRNA of galectin-9, the target prediction programs miRanda and TargetScan were used to predict miRNAs that possibly target galectin-9. miR-22, 296-3p, 455-5p and 491-5p were identified as potential miRNAs, and their expression levels were measured in colon cancer 

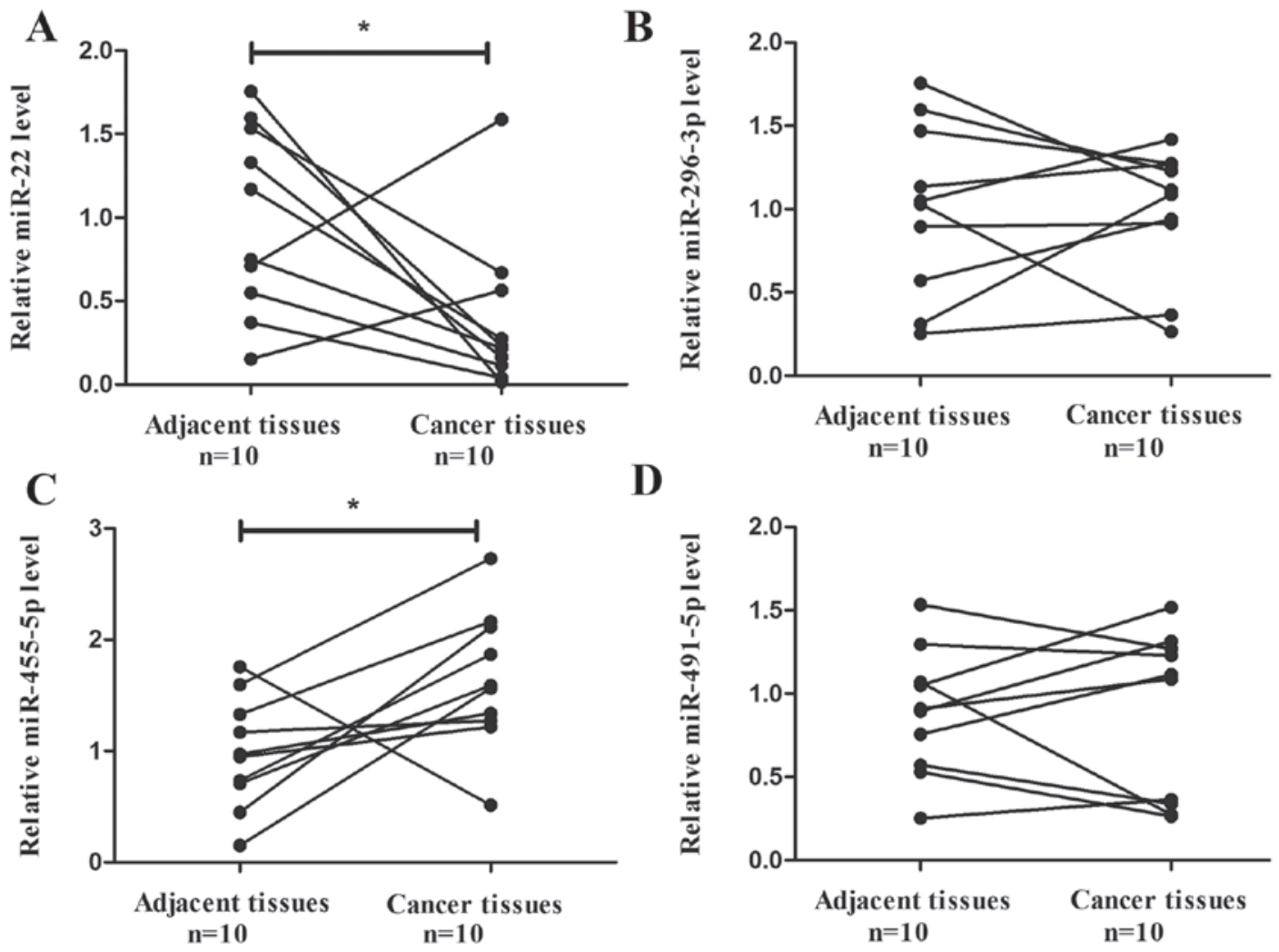

Figure 2. Expression levels of four miRNAs that may target galectin-9. (A) miR-22 was downregulated in colon cancer tissue compared with corresponding adjacent tissue, $\mathrm{n}=10$. (B) Increasing the level of miR-296-3p expression did not result in a significant difference between tumor and corresponding adjacent tissues. (C) miR-455-5p was significantly upregulated in colon cancer tissue compared with corresponding adjacent tissue, $n=10$. (D) Increasing the level of miR-491-5p expression did not result in a significant difference between tumor and corresponding adjacent tissues. " $\mathrm{P}<0.05$. miR, microRNA.

A
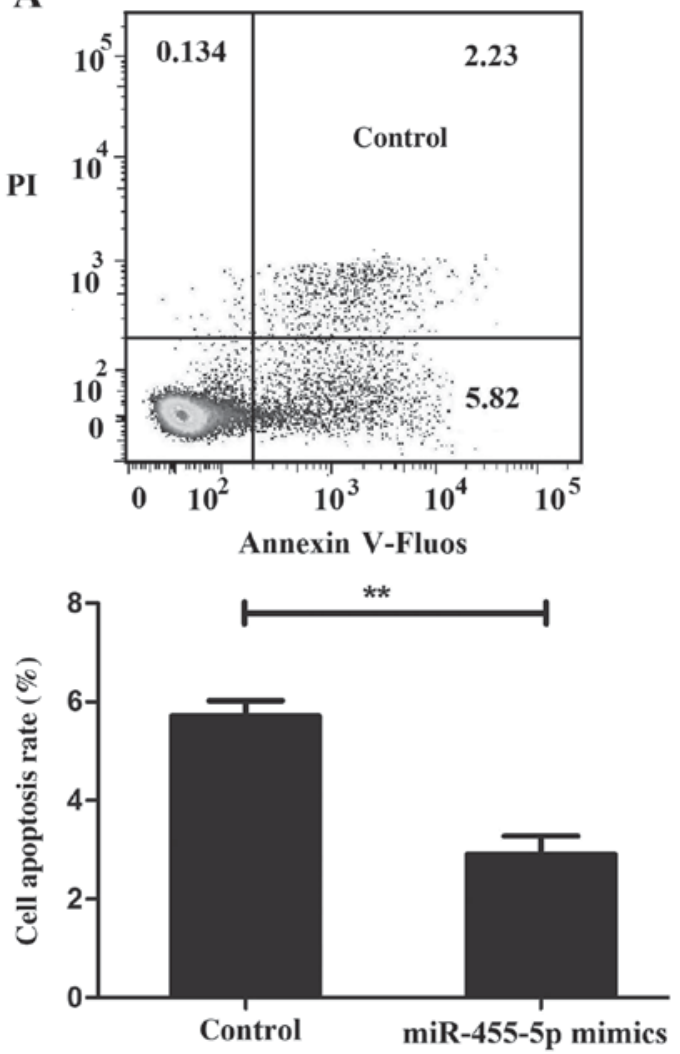

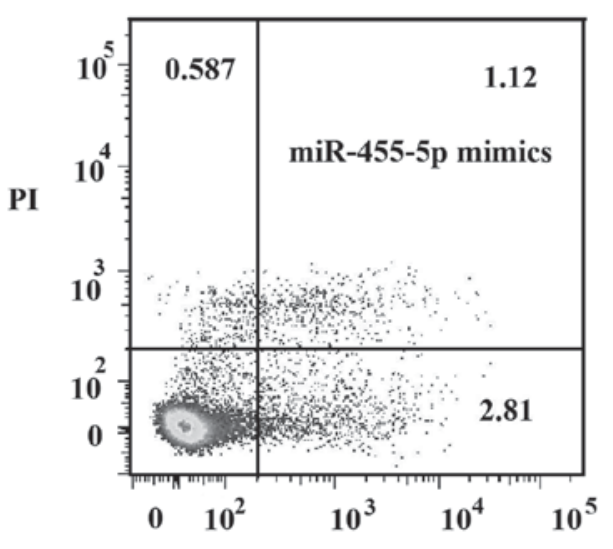

Annexin V-Fluos

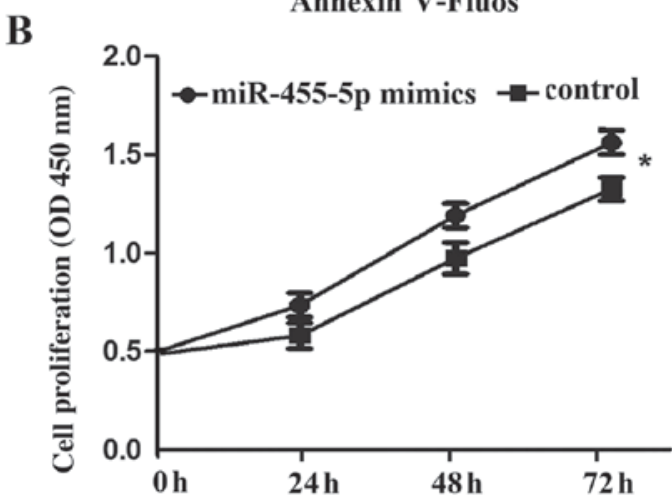

Figure 3. Role of miR-455-5p in colon cancer cell apoptosis and proliferation. (A) miR-455-5p inhibited HT29 cell apoptosis. (B) miR-455-5p promoted HT29 cell proliferation. ${ }^{*} \mathrm{P}<0.05,{ }^{* * *} \mathrm{P}<0.01$. miR, microRNA; PI, propidium iodide. 
A

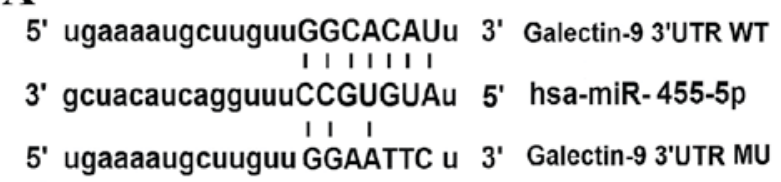

C
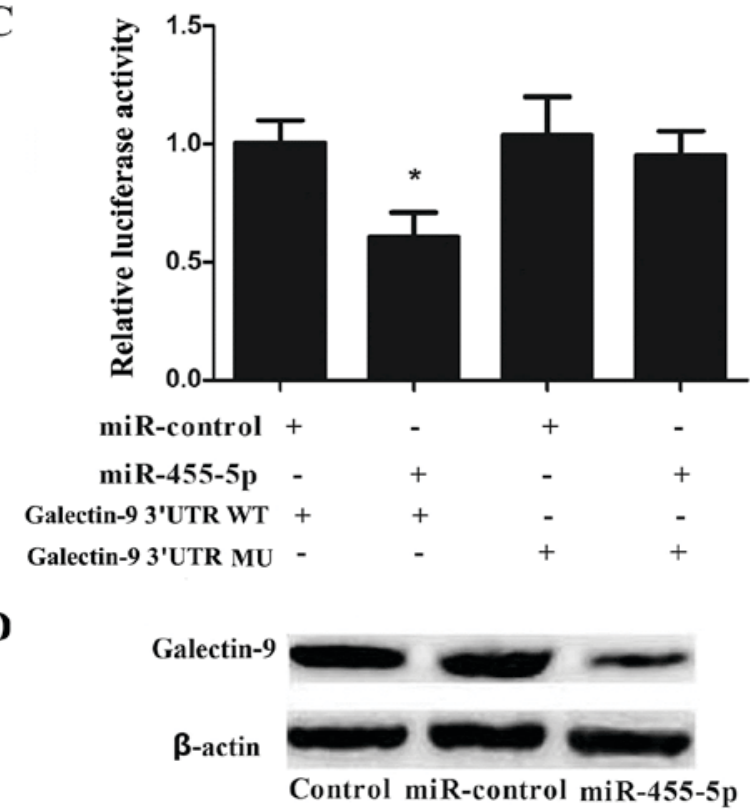
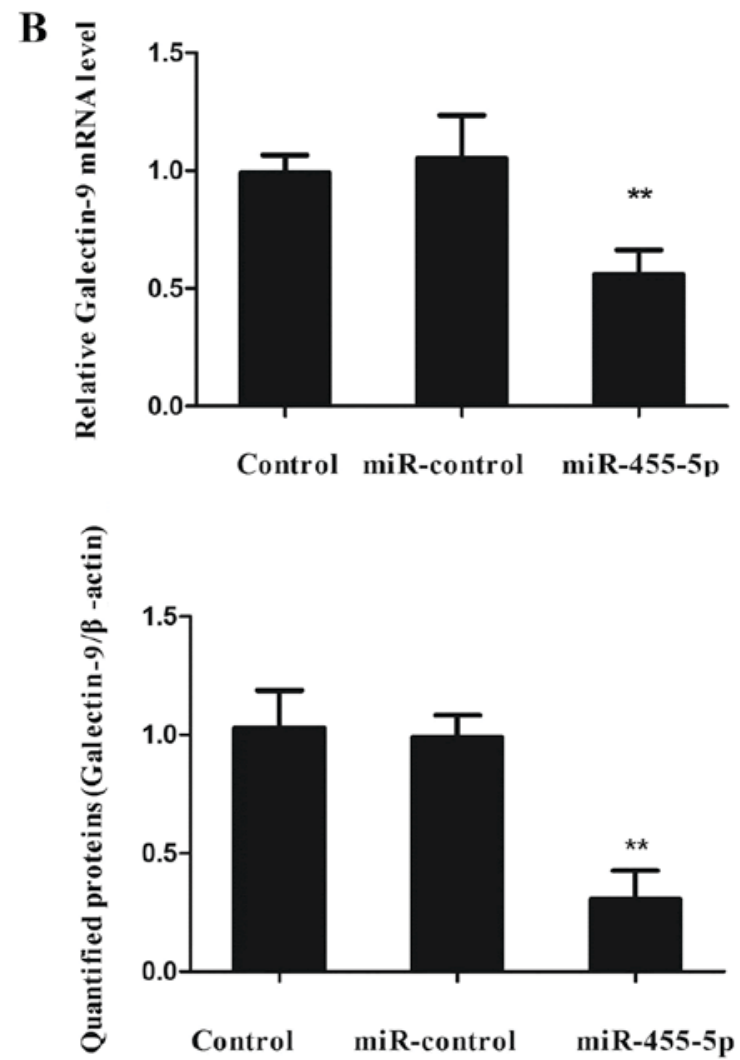

Figure 4. miR-455-5p directly targets and downregulates galectin-9 in HT29 cells. (A) Conserved or mutated forms of the miR-455-5p binding sequence were inserted into the luciferase gene to generate galectin-9 3'-UTR-WT or galectin-9 3'-UTR-MU plasmids, respectively. (B) Expression of galectin-9 mRNA was significantly downregulated following transfection with a miR-455-5p mimic. (C) miR-455-5p suppressed luciferase reporter gene activity in HT29 cells. (D) The expression of galectin-9 protein was significantly downregulated subsequent to transfection with miR-455-5p mimics. ${ }^{*} \mathrm{P}<0.05$, ${ }^{* *} \mathrm{P}<0.01$. UTR, untranslated region; WT, wild type; MU, mutant; mRNA, messenger RNA; miR, microRNA; hsa, Homo sapiens.

and corresponding adjacent tissues. Of these four miRNAs, miR-455-5p was significantly upregulated, while miR-22 was downregulated, in colon cancer tissue compared with the corresponding adjacent tissue. By contrast, miR-296-3p and 491-5p did not exhibit a significant difference. miR-455-5p has recently been shown to be important in the progression of numerous types of malignancy. Liu et al (36) identified that miR-455-5p was associated with anaplastic lymphoma kinase expression. Shoshan et al (37) confirmed that miR-455-5p contributes to melanoma growth and metastasis through the downregulation of the tumor-suppressor gene cytoplasmic polyadenylation element binding protein 1 . However, the exact role with respect to influencing cell proliferation and apoptosis, and the regulatory mechanism of miR-455-5p in colon cancer remains unclear. The present study demonstrated that miR-455-5p promoted HT29 cell proliferation and inhibited HT29 cell apoptosis. These results suggested that miR-455-5p serves an oncogenic role in colon cancer. In addition, miR-455-5p and galectin-9 expression exhibited an inverse correlation and role in influencing cell proliferation and apoptosis, which provides a foundation for additional investigation into their association.

To explore whether miR-455-5p is involved in the regulation of galectin-9 expression, a Dual-Luciferase Reporter Assay System was employed. The luciferase reporter assay indicated that the luciferase activity of the reporter containing the wide-type 3'-UTR of the galectin-9 gene decreased following treatment with miR-455-5p mimic, indicating that miR-455-5p suppresses gene expression through miR-455-5p-binding sequences at the 3'-UTR of galectin-9. In addition, RT-qPCR and western blot analysis revealed that the mRNA and protein expression of galectin-9 was inhibited by treatment with the miR-455-5p mimic in HT29 cells. These data suggest that miR-455-5p reduces galectin-9 expression by inhibiting translation and/or causing mRNA instability.

In summary, the present study provides evidence that miR-455-5p mediates the downregulation of galectin-9 in colon cancer. The present study demonstrated that miR-455-5p promoted HT29 cell proliferation and inhibited HT29 cell apoptosis by suppressing galectin- 9 expression. miRNA-455-5p functions as a potential oncogene in colon cancer, and the miRNA-455-5p/galectin-9 axis provides a novel insight into the pathogenesis of colon cancer.

\section{References}

1. Neri F, Dettori D, Incarnato D, Krepelova A, Rapelli S, Maldotti M, Parlato C, Paliogiannis P and Oliviero S: TET1 is a tumour suppressor that inhibits colon cancer growth by derepressing inhibitors of the WNT pathway. Oncogene 34: 4168-4176, 2015.

2. Slattery ML, Pellatt DF, Mullany LE, Wolff RK and Herrick JS: Gene expression in colon cancer: A focus on tumor site and molecular phenotype. Genes Chromosomes Cancer 54: 527-541, 2015. 
3. van Duijnhoven FJ, Bueno-De-Mesquita HB, Ferrari P, Jenab M, Boshuizen HC, Ros MM, Casagrande C, Tjønneland A, Olsen A, Overvad K, et al: Fruit, vegetables, and colorectal cancer risk: The European Prospective Investigation into Cancer and Nutrition. Am J Clin Nutr 89: 1441-1452, 2009.

4. McCormack VA and Boffetta P: Today's lifestyles, tomorrow's cancers: Trends in lifestyle risk factors for cancer in low- and middle-income countries. Ann Oncol 22: 2349-2357, 2011.

5. Kan JY, Hsu YL, Chen YH, Chen TC, Wang JY and Kuo PL: Gemifloxacin, a fluoroquinolone antimicrobial drug, inhibits migration and invasion of human colon cancer cells. Biomed Res Int 2013: 159786, 2013.

6. Abbadessa B, Agnew J, Bonomo G, et al: Overall survival is negatively impacted by postoperative complications following curative resection of rectal cancer but not colon cancer. Dis Colon Rectum 56: E261-E262, 2013.

7. Leffler H, Carlsson S, Hedlund M, Qian Y and Poirier F: Introduction to galectins. Glycoconj J 19: 433-440, 2004.

8. Wiersma VR, de Bruyn M, Helfrich W and Bremer E: Therapeutic potential of Galectin-9 in human disease. Med Res Rev 33 (Suppl 1): E102-E126, 2013.

9. Matsumoto R, Hirashima M, Kita H and Gleich GJ: Biological activities of ecalectin: A novel eosinophil-activating factor. J Immunol 168: 1961-1967, 2002.

10. Matsumoto R, Matsumoto H, Seki M, Hata M, Asano Y, Kanegasaki S, Stevens RL and Hirashima M: Human ecalectin, a variant of human galectin-9, is a novel eosinophil chemoattractant produced by T lymphocytes. J Biol Chem 273: 16976-16984, 1998.

11. Niwa H, Satoh T, Matsushima Y, Hosoya K, Saeki K, Niki T, Hirashima M and Yokozeki H: Stable form of galectin-9, a Tim-3 ligand, inhibits contact hypersensitivity and psoriatic reactions: A potent therapeutic tool for Th1- and/or Th17-mediated skin inflammation. Clin Immunol 132: 184-194, 2009.

12. Abedin MJ, Kashio Y, Seki M, Nakamura K and Hirashima M Potential roles of galectins in myeloid differentiation into three different lineages. J Leukoc Biol 73: 650-656, 2003.

13. Kashio Y, Nakamura K, Abedin MJ, Seki M, Nishi N, Yoshida N, Nakamura T and Hirashima M: Galectin-9 induces apoptosis through the calcium-calpain-caspase-1 pathway. J Immunol 170 : 3631-3636, 2003.

14. Nobumoto A, Nagahara K, Oomizu S, Katoh S, Nishi N, Takeshita K, Niki T, Tominaga A, Yamauchi A and Hirashima M: Galectin-9 suppresses tumor metastasis by blocking adhesion to endothelium and extracellular matrices. Glycobiology 18 : 735-744, 2008

15. Zhang ZY, Dong JH, Chen YW, Wang XQ, Li CH, Wang J, Wang GQ, Li HL and Wang XD: Galectin-9 acts as a prognostic factor with antimetastatic potential in hepatocellular carcinoma. Asian Pac J Cancer Prev 13: 2503-2509, 2012.

16. Ambros V: The functions of animal microRNAs. Nature 431: 350-355, 2004

17. Kozak M: Faulty old ideas about translational regulation paved the way for current confusion about how microRNAs function. Gene 423: 108-115, 2008.

18. Qu J, Zhao L, Zhang P, Wang J, Xu N, Mi W, Jiang X, Zhang C and Qu J: MicroRNA-195 chemosensitizes colon cancer cells to the chemotherapeutic drug doxorubicin by targeting the first binding site of BCL2L2 mRNA. J Cell Physiol 230: 535-545, 2015.

19. Friedman RC, Farh KK, Burge CB and Bartel DP: Most mammalian mRNAs are conserved targets of microRNAs. Genome Res 19: 92-105, 2009.
20. Ren XS, Yin MH, Zhang X, Wang Z, Feng SP, Wang GX, Luo YJ, Liang PZ, Yang XQ, He JX and Zhang BL: Tumor-suppressive microRNA-449a induces growth arrest and senescence by targeting E2F3 in human lung cancer cells. Cancer Lett 344: 195-203, 2014

21. Kasashima K, Nakamura Y and Kozu T: Altered expression profiles of microRNAs during TPA-induced differentiation of HL-60 cells. Biochem Biophys Res Commun 322: 403-410, 2004.

22. McManus MT: MicroRNAs and cancer. Semin Cancer Biol 13: 253-258, 2003

23. Miao J, Wu S, Peng Z, Tania M and Zhang C: MicroRNAs in osteosarcoma: Diagnostic and therapeutic aspects. Tumour Biol 34: 2093-2098, 2013.

24. Cimmino A, Calin GA, Fabbri M, Iorio MV, Ferracin M, Shimizu M, Wojcik SE, Aqeilan RI, Zupo S, Dono M, et al: miR-15 and miR-16 induce apoptosis by targeting BCL2. Proc Natl Acad Sci USA 102: 13944-13949, 2005.

25. Livak KJ and Schmittgen TD: Analysis of relative gene expression data using real-time quantitative PCR and the 2(-Delta Delta C(T)) method. Methods 25: 402-408, 2001.

26. Yang Q, Jiang W, Zhuang C, Geng Z, Hou C, Huang D, Hu L and Wang X: microRNA-22 downregulation of galectin-9 influences lymphocyte apoptosis and tumor cell proliferation in liver cancer. Oncol Rep 34: 1771-1778, 2015.

27. Thijssen VL,Hulsmans S and Griffioen AW: The galectin profile of the endothelium: Altered expression and localization in activated and tumor endothelial cells. Am J Pathol 172: 545-553, 2008.

28. Türeci O, Schmitt H, Fadle N, Pfreundschuh M and Sahin U: Molecular definition of a novel human galectin which is immunogenic in patients with Hodgkin's disease. J Biol Chem 272: 6416-6422, 1997.

29. Liu Z, Han H, He X, Li S, Wu C, Yu C and Wang S: Expression of the galectin-9-Tim-3 pathway in glioma tissues is associated with the clinical manifestations of glioma. Oncol Lett 11: 1829-1834, 2016.

30. Heusschen R, Griffioen AW and Thijssen VL: Galectin-9 in tumor biology: A jack of multiple trades. Biochim Biophys Acta 1836: 177-185, 2013.

31. Saita N, Goto E, Yamamoto T, Cho I, Tsumori K, Kohrogi H, Maruo K, Ono T, Takeya M, Kashio Y, et al: Association of galectin-9 with eosinophil apoptosis. Int Arch Allergy Immunol 128: 42-50, 2002.

32. Kobayashi T, Kuroda J, Ashihara E, Oomizu S, Terui Y, Taniyama A, Adachi S, Takagi T, Yamamoto M, Sasaki N, et al: Galectin-9 exhibits anti-myeloma activity through JNK and p38 MAP kinase pathways. Leukemia 24: 843-850, 2010.

33. Iorio MV and Croce CM: MicroRNAs in cancer: Small molecules with a huge impact. J Clin Oncol 27: 5848-5856, 2009.

34. Calin GA and Croce CM: MicroRNA signatures in human cancers. Nat Rev Cancer 6: 857-866, 2006.

35. Wang YW, Shi DB, Chen X, Gao C and Gao P: Clinicopathological significance of microRNA-214 in gastric cancer and its effect on cell biological behaviour. PLoS One 9: e91307, 2014.

36. Liu CL, Iqbal J, Teruya-Feldstein J, Shen Y, Dabrowska MJ, Dybkaer K, Lim MS, Piva R, Barreca A, Pellegrino E, et al: microRNA expression profiling identifies molecular signatures associated with anaplastic large cell lymphoma. Blood 122: 2083-2092, 2013

37. Shoshan E, Mobley AK, Braeuer RR, Kamiya T, Huang L, Vasquez ME, Salameh A, Lee HJ, Kim SJ, Ivan C, et al: Reduced adenosine-to-inosine miR-455-5p editing promotes melanoma growth and metastasis. Nat Cell Biol 17: 311-321, 2015. 